\title{
Genetic changes that increase 5-hydroxymethyl furfural resistance in ethanol-producing Escherichia coli LY180
}

\author{
E. N. Miller • P. C. Turner • L. R. Jarboe • \\ L. O. Ingram
}

Received: 18 November 2009/Revised: 14 January 2010/Accepted: 14 January 2010/Published online: 4 February 2010

(C) The Author(s) 2010. This article is published with open access at Springerlink.com

\begin{abstract}
The ability of a biocatalyst to tolerate furan inhibitors present in hemicellulose hydrolysates is important for the production of renewable chemicals. This study shows EMFR9, a furfural-tolerant mutant of ethanologenic E. coli LY180, has also acquired tolerance to 5-hydroxymethyl furfural (5-HMF). The mechanism of action of 5-HMF and furfural appear similar. Furan tolerance results primarily from lower expression of $y q h D$ and $d k g A$, two furan reductases with a low $\mathrm{K}_{\mathrm{m}}$ for NADPH. Furan tolerance was also increased by adding plasmids encoding a NADPH/ NADH transhydrogenase (pntAB). Together, these results support the hypothesis that the NADPHdependent reduction of furans by YqhD and DkgA inhibits growth by competing with biosynthesis for this limiting cofactor.
\end{abstract}

Keywords Furfural $\cdot$ Hexose $\cdot$ 5-Hydroxymethyl furfural $\cdot \mathrm{NADPH} \cdot$ Pentose $\cdot$ Transhydrogenase

\section{Introduction}

Lignocellulosic biomass represents a potential feedstock for microbial conversion to renewable fuels and

E. N. Miller · P. C. Turner · L. R. Jarboe ·

L. O. Ingram $(\varangle)$

Department of Microbiology and Cell Science, University of Florida, Gainesville, FL 32611, USA

e-mail: ingram@ufl.edu chemicals. Prior to fermentation, carbohydrate components (cellulose and hemicellulose) must be converted to soluble sugars using acids, enzymes, or a combination (Cheng et al. 2008; Wyman et al. 2005; Um et al. 2003). During steam pretreatment with mineral acids, 5-hydroxymethyl furfural (5-HMF) and furfural are produced as minor but toxic side products from the dehydration of hexose and pentose sugars, respectively (Martinez et al. 2000a; Palmqvist and Hahn-Hagerdal 2000b). 5-HMF has been shown to retard growth and fermentation of ethanologenic E. coli (Zaldivar et al. 1999) and Saccharomyces cerevisiae (Almeida et al. 2008; Palmqvist and HahnHagerdal 2000a; Taherzadeh et al. 2000).

Furans can be removed from hemicellulose hydrolysates by over-liming to $\mathrm{pH} 10$ at elevated temperatures (Martinez et al. 2000a). This process requires the efficient separation of hydrolysate syrups from cellulosic fibers, specialized equipment for lime mixing, separation of syrups from insoluble calcium salts, and creates a solid waste for disposal. The development of furan-resistant biocatalysts could eliminate much of this process complexity. Several enteric bacterial genera (Klebsiella, Enterobacter, Escherichia, Citrobacter, Edwardsiella, Proteus) as well as yeasts convert 5-HMF into 5-hydroxymethyl furfuryl alcohol, a less toxic compound (Boopathy et al. 1993; Palmqvist and Hahn-Hagerdal 2000a; Zaldivar et al. 1999). S. cerevisiae produces multiple oxidoreductases (YGL157W, ADH6, and a mutated $\mathrm{ADH} 1)$ that can reduce both 5-HMF and furfural to 
less toxic products (Almeida et al. 2008, 2009; Heer et al. 2009; Liu and Moon 2009). Increased expression of these genes was shown to be beneficial for some aspects of 5-HMF tolerance although none have been shown to increase the minimum inhibitory concentration of furfural. Gorsich et al. (2006) identified many gene inactivations in $S$. cerevisiae that increased sensitivity to furfural and 5-HMF. Overexpression of one gene, ZWF1 (glucose 6-phosphate dehydrogenase), increased tolerance to furfural.

A furfural-resistant mutant (strain EMFR9) of an ethanologenic E. coli was recently isolated (Miller et al. 2009b). In contrast to studies with yeast, resistance in EMFR9 was found to result from decreased expression of two NADPH-dependent furfural oxidoreductases ( $y q h D$ and $d k g A$ ) which encode half of the cellular furfural reductase activity. Like biosynthetic enzymes, both have low $\mathrm{Km}$ values for NADPH.

In this study, we demonstrate that EMFR9 is also resistant to 5-HMF. Both furans appear to inhibit the growth of $E$. coli in xylose minimal media by a similar mechanism. Furan reduction by YqhD and DkgA limits biosynthesis by depleting NADPH pools.

\section{Materials and methods}

Strains, media, and growth conditions

Strains and plasmids used in this study have been previously described (Miller et al. 2009a, b). These include LY180 (an ethanologenic derivative of E. coli), EMFR9 (furfural-tolerant derivative of LY180), LY180 $\Delta y q h D$, LY180 $\Delta d k g A$, LY180 $\Delta y q h D$ $\Delta \mathrm{dkgA}$, pLOI4301 containing $y q h D$. Plasmids pLOI4303 containing $d k g A$ (Miller et al. 2009b), and pLOI4316 containing pntAB (Miller et al. 2009a) were also used. Cultures were grown at $37^{\circ} \mathrm{C}$ in $\mathrm{AM} 1$ minimal media (Martinez et al. 2007) containing $20 \mathrm{~g}^{-1}$ xylose (solid medium), $50 \mathrm{~g}^{-1}$ xylose (Bioscreen $\mathrm{C}$ growth analyzer and tube cultures), or $100 \mathrm{~g} \mathrm{l}^{-1}$ (pH-controlled fermentations).

Tolerance to HMF was tested using $13 \times 100 \mathrm{~mm}$ closed tubes containing $4 \mathrm{ml}$ AM1 and 5-HMF as indicated. When appropriate, antibiotics were included for plasmid maintenance. Tubes were inoculated to an initial density of $0.05 \mathrm{OD}_{550 \mathrm{~nm}}$. Growth was measured as the $\mathrm{OD}_{550}$ value after incubation
(60 rpm) for $48 \mathrm{~h}$. To examine the effects of pntAB on furan tolerance, a multiwall plate containing $400 \mu \mathrm{AM} 1$ (and 5-HMF or furfural) per well was inoculated as above. $\mathrm{OD}_{(420-580 \mathrm{~nm}}$ bandwidth) was measured for $72 \mathrm{~h}$ using a Bioscreen $\mathrm{C}$ growth analyzer (Oy Growth Curves, Helsinki, Finland).

For fermentation experiments, seed cultures of LY180 and EMFR9 were grown overnight in small fermentors $\left(37^{\circ} \mathrm{C}, 200 \mathrm{rpm}\right)$ containing $350 \mathrm{ml}$ of AM1 medium. Broth was maintained at $\mathrm{pH} 6.5$ by the automatic addition of $2 \mathrm{~N} \mathrm{KOH}$. Upon reaching mid$\log$ phase, experimental fermenters were inoculated to an initial cell density of $0.1 \mathrm{OD}_{550}(33 \mathrm{mg}$ dry cell weight $\left.\mathrm{l}^{-1}\right)$. Cell mass $\left(\mathrm{OD}_{550}\right)$ and furan levels were monitored at $12-\mathrm{h}$ intervals as described previously (Martinez et al. 2000b).

Furan reduction in vivo was measured using $\mathrm{pH}$ controlled fermenters. Furans were added when the cultures reached approximately $1 \mathrm{OD}_{550}$ using a $10 \%$ w/v stock solution. Cell mass and 5-HMF were measured after $0,15,30$, and $60 \mathrm{~min}$.

In vitro furan reduction

Culture tubes $(13 \times 100 \mathrm{~mm})$ containing AM1 and $0.1 \mathrm{mM}$ IPTG were inoculated to $0.05 \mathrm{OD}_{550}$ and incubated at $37^{\circ} \mathrm{C}$. These were harvested at a density of 1-2 $\mathrm{OD}_{550}$. Cell pellets were washed once with $100 \mathrm{mM}$ potassium phosphate buffer $(\mathrm{pH} \mathrm{7.0)}$, and resuspended in buffer at a density of $10 \mathrm{OD}_{550}$. Samples $(1 \mathrm{ml})$ were added to $2 \mathrm{ml}$ tubes containing Lysing Matrix B and disrupted (20 s) using a FastPrep-24 (MP Biomedicals, Solon, OH). Furandependent oxidation of NADPH was measured at $340 \mathrm{~nm}$ using a DU 800 spectrophotometer (Beckman Coulter, Fullerton, CA). Reactions (200 $\mu$ total volume; $37^{\circ} \mathrm{C}$ ) contained $50 \mu \mathrm{l}$ crude extract, $0.2 \mathrm{mM}$ NADPH, and $20 \mathrm{mM}$ 5-HMF. Protein was measured using the BCA assay (Thermo Scientific, Rockford, IL).

Statistical analysis

Data are presented as an average $\pm \mathrm{SD}(n \geq 3)$. Statistical comparisons (2-tailed student $t$ test) were made using Graphpad Prism software (La Jolla, CA). 


\section{Results}

Strain EMFR9 exhibits increased tolerance to 5 -HMF

Mutations present in the furfural-resistant mutant, EMFR9, also increased resistance to 5-HMF (Fig. 1). At $1 \mathrm{~g} \mathrm{5-HMF} 1^{-1}$, growth and ethanol production by EMFR9 were equal to that of LY180 (parent) in the absence of 5-HMF (Fig. 1a, b). 5-HMF was rapidly metabolized by EMFR9 during the initial $24 \mathrm{~h}$ of fermentation with no detrimental effect on cell yield or ethanol yield. The growth of LY180 was completely inhibited by $1.0 \mathrm{~g} \mathrm{5-HMF} 1^{-1}$, although 5-HMF levels declined slowly during incubation (Fig. 1a, b, c). No decline was observed without inoculation (data not shown) confirming that this is the result of metabolic activity.

With EMFR9, ethanol production and growth were slowed by inclusion of $2.5 \mathrm{~g} 5$-HMF $1^{-1}$ but proceeded to completion after $96 \mathrm{~h}$ (Fig. 1d, e, f). Cell and ethanol yields with this higher level of 5-HMF were comparable to LY180 without 5-HMF. The level of 5-HMF declined rapidly and completely with EMFR9. With LY180, metabolism of 5-HMF was slow and incomplete (Fig. 1f).

\section{Effects of YqhD and DkgA on 5-HMF tolerance}

Furfural tolerance in EMFR9 was previously demonstrated to result from the silencing of two NADPHdependent oxidoreductases, YqhD and DkgA (Miller et al. 2009b). Genes encoding these activities were cloned into pCR2.1 TOPO, transformed into EMFR9, and induced with $0.1 \mathrm{mM}$ IPTG. Cells were harvested, disrupted, and tested for 5-HMF reductase activity (Fig. 2a). Expression of $y q h D$ and $d k g A$ individually from plasmids resulted in a 5-fold increase in the rate of 5-HMF-dependent oxidation of NADPH, confirming that $\mathrm{YqhD}$ and DkgA use 5-HMF as a substrate.

The individual expression of $y q h D$ and $d k g A$ from plasmids decreased the tolerance of EMFR9 to 5-HMF (Fig. 2b). Addition of kanamycin $\left(12.5 \mathrm{mg} \mathrm{l}^{-1}\right)$ for plasmid maintenance decreased 5-HMF tolerance in all strains, requiring the use of a lower concentration of
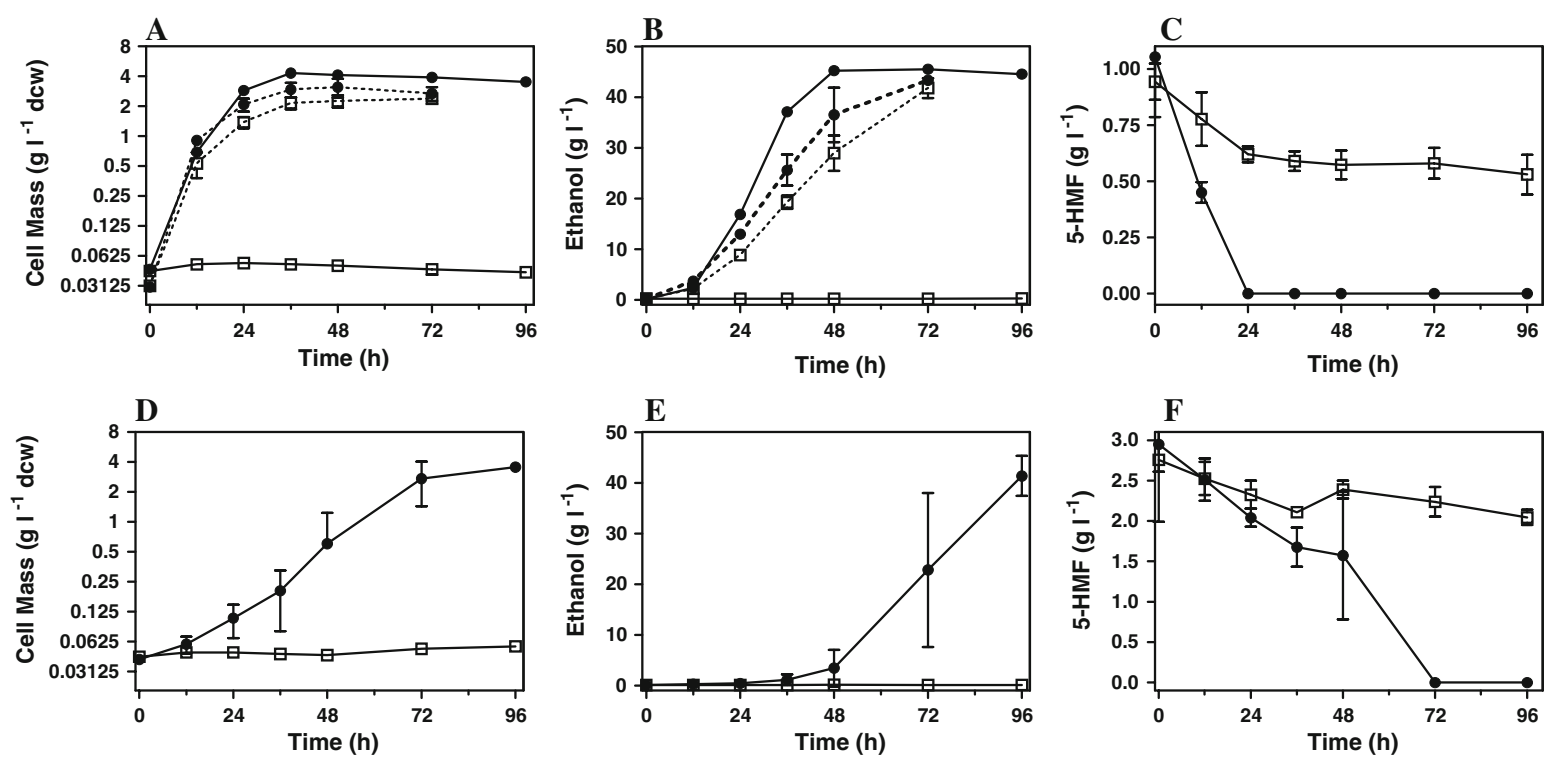

Fig. 1 Effect of 5-HMF on anaerobic growth and fermentation. Cells were grown in AM1 mineral salts media with xylose $\left(100 \mathrm{~g}\right.$ xylose $\left.1^{-1}\right)$. a Cell mass during growth with $1 \mathrm{~g}$ 5 -HMF $1^{-1}$; b ethanol production during fermentation with $1 \mathrm{~g}$ 5 -HMF $1^{-1}$; c reduction of 5-HMF $\left(1.0 \mathrm{~g} \mathrm{l}^{-1}\right)$ during fermentation; d cell mass during growth with $2.5 \mathrm{~g} 5$-HMF $1^{-1}$; e ethanol production during fermentation with $2.5 \mathrm{~g}$ 5 -HMF $1^{-1}$; f reduction of 5-HMF (2.5 g 5-HMF $\left.1^{-1}\right)$ during fermentation. Parallel fermentations without 5-HMF are included (dashed lines) in panels $\mathbf{a}$ and $\mathbf{b}$ for comparison. All data are plotted as a mean with standard deviation $(n=3)$. Symbols for all: open square, LY180; and filled circle, EMFR9 

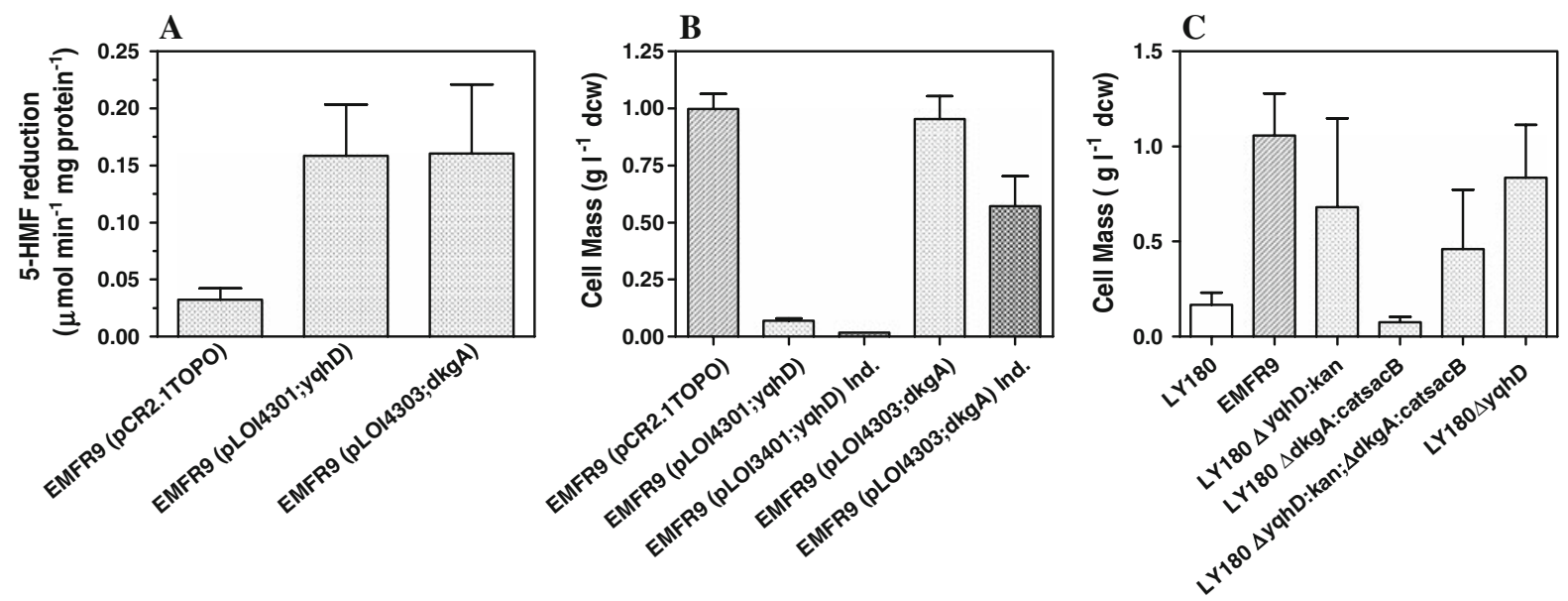

Fig. 2 Effect of YqhD and DkgA on the in vitro reduction of 5-HMF and on 5-HMF tolerance. a Specific activity for 5-HMF reduction in vitro. Activity was measured in lysed cell extracts (2 mM NADPH, $20 \mathrm{mM}$ 5-HMF). b Effect of $y q h D$ and $d k g A$ expression from plasmids on the cell yield of EMFR9 (resistant mutant). Experiments were performed in tube cultures with AM1 medium containing $50 \mathrm{~g}$ xylose $1^{-1}$ and $1.0 \mathrm{~g}$ 5-HMF $1^{-1}$

5-HMF $\left(1 \mathrm{~g} \mathrm{l}^{-1}\right)$ in this experiment. Plasmid pCR2.1 is leaky for the expression of cloned genes in the absence of IPTG (Purvis et al. 2005). Even uninduced expression of $y q h D$ was sufficient to restore the sensitivity of EMFR9 to 5-HMF. Growth inhibition by $5-\mathrm{HMF}$ was further increased by $y q h D$ induction. Expression of $d k g A$ was less effective and required induction to restore 5-HMF sensitivity in EMFR9. Differences in effectiveness between these two oxidoreductases are consistent with the lower apparent $\mathrm{K}_{\mathrm{m}}$ of YqhD $(8 \mu \mathrm{M})$ for NADPH compared to $23 \mu \mathrm{M}$ for DkgA (Miller et al. 2009b).

Deletion of $y q h D$ from LY180 increased tolerance

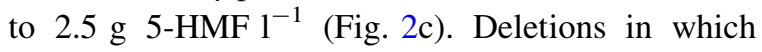
markers remained in the chromosome were less effective but confirmed that the inactivation of $y q h D$ was beneficial for 5-HMF tolerance in all cases.

Increasing the availability of NADPH increases 5-HMF tolerance

The proton-translocating transhydrogenase pntAB (Keseler et al. 2009) was over-expressed in LY180 (Fig. 3) to increase the availability of NADPH. In the absence of inhibitor (Fig. 3a), both LY180 with the vector (control) and LY180 (pTrc99a pntAB) grew at
(48 $\mathrm{h}$ incubation). Note that inclusion of kanamycin for plasmid maintenance lowers 5-HMF tolerance. Induced (Ind.) were grown with $0.1 \mathrm{mM}$ IPTG. c Effect of $y q h D$ and $d k g A$ deletions on the cell yield of LY180 (parent). Experiments were performed in tube cultures with AM1 medium containing $50 \mathrm{~g}$ xylose $1^{-1}$ and $2.5 \mathrm{~g} \mathrm{5-HMF} 1^{-1}$ (48 h incubation). All data are plotted as a mean with standard deviation $(n=4)$

the same rate. Induction of LY180 (pTrc99a-pntA) with IPTG $(0.01 \mathrm{mM})$ was detrimental in the absence of 5-HMF. Uninduced LY180 (pTcr99a pntAB), however, grew more rapidly than the vector control (Fig. 3b, c) in the presence of 5-HMF $(0.9$ and $\left.1.8 \mathrm{~g}^{-1}\right)$. A similar benefit of $p n t A B$ was observed previously with furfural (Miller et al. 2009a). Thus the inhibition of growth by both furans appears to result from furan reduction, depleting the pool of NADPH required for biosynthesis. In addition, overexpression of pntAB led to an increase in overall growth after $72 \mathrm{~h}$, even in the absence of furfural, indicating that biosynthesis may be limited by NADPH under these conditions.

Sulfur assimilation and cysteine biosynthesis have a particularly high requirement for NADPH. Supplementing with cysteine was previously shown to increase furfural tolerance in E. coli LY180 (Miller et al. 2009a) but was of less benefit for 5-HMF tolerance (Fig. 4). Growth of LY180 was partially inhibited by $1 \mathrm{~g} 5$-HMF $1^{-1}$ and completely restored by supplementing with $100 \mu \mathrm{M}$ cysteine. Growth in the presence of $2.5 \mathrm{~g} \mathrm{5-HMF} 1^{-1}$ was not restored by 100 or $1,000 \mu \mathrm{M}$ cysteine (Fig. 4b). Unlike furfural, cysteine supplements did not increase the MIC for 5-HMF. 

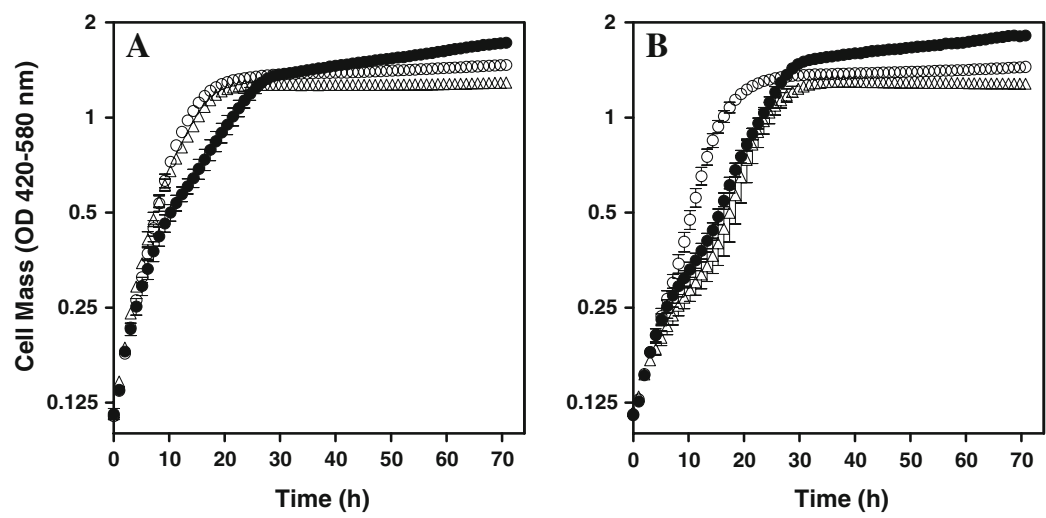

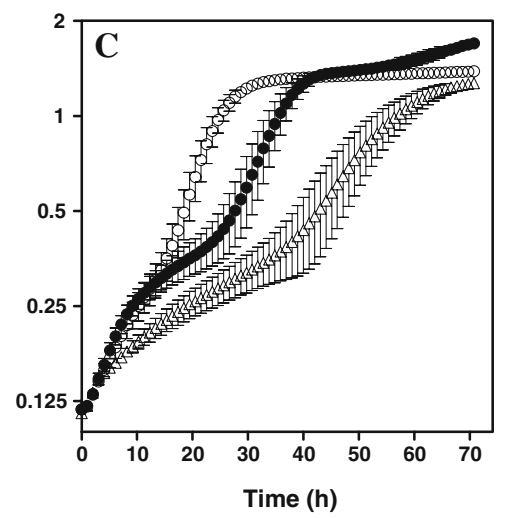

Fig. 3 Effect of pntAB expression from plasmids on 5-HMF tolerance. Experiments were conducted using the Bioscreen $\mathrm{C}$ growth curve analyzer with AM1 medium containing $50 \mathrm{~g}$ xylose $1^{-1}$ and 5-HMF as indicated. All data are plotted as a mean with standard deviation $(n=10)$. Connecting points have

\section{Conclusions}

Selection of an E. coli mutant (EMFR9) for resistance to growth inhibition by furfural (Miller et al. 2009b) was accompanied by resistance to 5-HMF. Both of these furans are important toxins in acid hydrolysates of hemicellulose (Almeida et al. 2009; Gorsich et al. 2006; Zaldivar et al. 1999). At low concentration, both furans were less toxic to cellular functions in E. coli than the consequences of their metabolism. During catabolism, low $\mathrm{K}_{\mathrm{m}} \mathrm{NADPH}$-dependent oxidoreductases (YqhD and DkgA) compete with biosynthesis for this key cofactor and inhibit growth (Fig. 5). Genes encoding these enzymes (yqhD and $d k g A$ ) were silenced in the furan-resistant mutant. Sensitivity was restored by plasmids encoding the production of either enzyme. Resistance was acquired in the parent by deletion of $y q h D$.

Cells are quite limited in their ability to produce NADPH during fermentative growth on xylose. The most likely source of NADPH under these conditions would be the transhydrogenases (sthA and pntAB). Plasmid expression of pntAB was found to increase resistance to both furfural (Miller et al. 2009a, b) and 5-HMF. A small amount of NADPH would be produced by isocitrate dehydrogenase (icd) during 2-ketoglutarate biosynthesis. Additional NADPH could be produced during gluconeogenesis using malic enzyme ( $m a e B$ ) and by the pentose phosphate pathway (glucose dehydrogenase, gnd; glucose 6-phosphate dehydrogenase, $z w f)$. been omitted for clarity. a No supplement; $\mathbf{b}$ supplemented with $0.9 \mathrm{~g} 5-\mathrm{HMF}^{-1}$; and c supplemented with $1.8 \mathrm{~g} \mathrm{5-HMF} 1^{-1}$. Symbols for all: open triangle, LY180 (pTrc99a-control); open circle, LY180 (pTrc99a-pntAB) uninduced; filled circle, LY180 (pTrc99a-pntAB) induced with $0.01 \mathrm{mM}$ IPTG
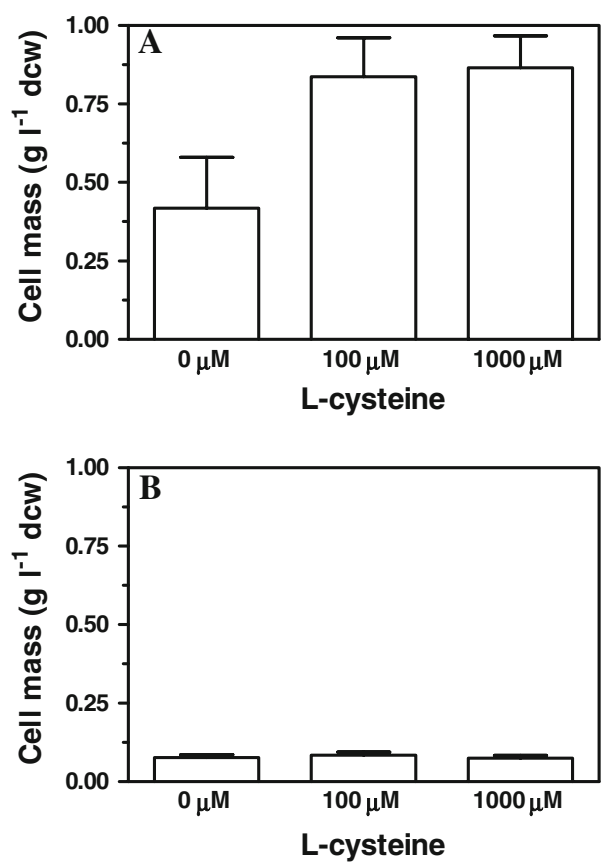

Fig. 4 Effect of L-cysteine on 5-HMF tolerance of LY180. Experiments were performed in tube cultures with AM1 medium containing $50 \mathrm{~g}$ xylose $1^{-1}$ and 5-HMF (24 h incubation). Cultures were supplemented with filter-sterilized L-cysteine as indicated. All data are plotted as a mean with standard deviation $(n=4)$. a 1 g $5-\mathrm{HMF}^{-1}$; b 2 g $5-\mathrm{HMF} 1^{-1}$

The effects of 5-HMF and furfural may not be identical, however. Growth inhibition by these compounds differed in the presence of supplemental cysteine. Sulfur assimilation and cysteine have a high 


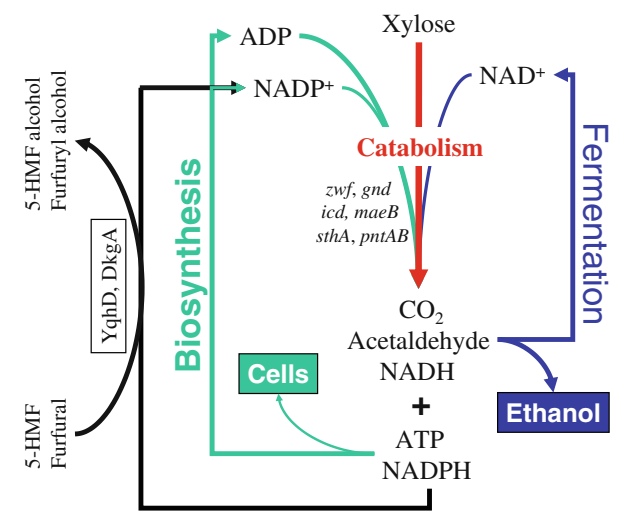

Fig. 5 Proposed mechanism for growth inhibition by furans during ethanol fermentation. Xylose or other sugar is initially catabolized to $\mathrm{CO}_{2}$, acetaldehyde, and low levels of other intermediates. Energy is conserved in the form of ATP. NADH serves as the dominant electron carrier, and is regenerated during fermentation by the reduction of acetaldehyde to ethanol. Small amounts of NADPH are produced for essential biosynthetic reactions by genes such as those listed. NADP ${ }^{+}$ and ADP are regenerated during biosynthesis (and maintenance). Two oxidoreductases (YqhD and DkgA) with low apparent $K_{m}$ values for NADPH are proposed to inhibit biosynthesis and growth by depleting the supply of NADPH

requirement for NADPH. Addition of low levels of cysteine increased the MIC of furfural, presumably by sparing NADPH for other biosynthetic functions (Miller et al. 2009a). Unlike furfural, cysteine addition provided a very limited benefit for 5-HMF tolerance. Thus it is likely that both 5-HMF and furfural have additional inhibitory actions that are not shared.

Acknowledgments The authors gratefully acknowledge research support by grants from the U.S. Department of Energy (DE-FG36-08GO88142, DE-FC36-GO17058). This work was facilitated by the EcoCyc database (Keseler et al. 2009).

Open Access This article is distributed under the terms of the Creative Commons Attribution Noncommercial License which permits any noncommercial use, distribution, and reproduction in any medium, provided the original author(s) and source are credited.

\section{References}

Almeida JRM, Roder A, Modig T, Laadan B, Liden G, Gorwa-Grauslund MF (2008) NADH- vs NADPH-coupled reduction of 5-hydroxymethyl furfural (HMF) and its implications on product distribution in Saccharomyces cerevisiae. Appl Microbiol Biotechnol 78:939-945
Almeida JRM, Bertilsson M, Gorwa-Grauslund MF, Gorsich S, Liden G (2009) Metabolic effects of furaldehydes and impacts on biotechnological processes. Appl Microbiol Biotechnol 82:625-638

Boopathy R, Bokang H, Daniels L (1993) Biotransformation of furfural and 5-hydroxymethyl furfural by enteric bacteria. J Ind Microbiol 11:147-150

Cheng KK, Cai BY, Zhang JA, Ling HZ, Zhou YH, Ge JP, Xu JM (2008) Sugarcane bagasse hemicellulose hydrolysate for ethanol production by acid recovery process. Biochem Eng J 38:105-109

Gorsich SW, Dien BS, Nichols NN, Slininger PJ, Liu ZL, Skory CD (2006) Tolerance to furfural-induced stress is associated with pentose phosphate pathway genes $Z W F 1$, GND1, RPE1, and TKL1 in Saccharomyces cerevisiae. Appl Microbiol Biotechnol 71:339-349

Heer D, Heine D, Sauer U (2009) Resistance of Saccharomyces cerevisiae to high furfural concentration is based on NADPH-dependent reduction by at least two oxidoreductases. Appl Environ Microbiol. doi:10.1128/AEM.01649-9

Keseler IM, Bonavides-Martinez C, Collado-Vides J, GamaCastro S, Gunsalus RP, Johnson DA, Krummenacker M, Nolan LM, Paley S, Paulsen IT, Peralta-Gil M, SantosZavaleta A, Shearer AG, Karp PD (2009) EcoCyc: a comprehensive view of Escherichia coli biology. Nucleic Acids Res 37:D464-D470

Liu ZL, Moon J (2009) A novel NADPH-dependent aldehyde reductase gene from Saccharomyces cerevisiae NRRL Y-12632 involved in the detoxification of aldehyde inhibitors derived from lignocellulosic biomass conversion. Gene 446:1-10

Martinez A, Rodriguez ME, York SW, Preston JF, Ingram LO (2000a) Effects of $\mathrm{Ca}(\mathrm{OH})_{2}$ treatments ("overliming") on the composition and toxicity of bagasse hemicellulose hydrolysates. Biotechnol Bioeng 69:526-536

Martinez A, Rodriguez ME, York SW, Preston JF, Ingram LO (2000b) Use of UV absorbance to monitor furans in dilute acid hydrolysates of biomass. Biotechnol Prog 16:637-641

Martinez A, Grabar TB, Shanmugam KT, Yomano LP, York SW, Ingram LO (2007) Low salt medium for lactate and ethanol production by recombinant Escherichia coli B. Biotechnol Lett 29:397-404

Miller EN, Jarboe LR, Turner PC, Pharkya P, Yomano LP, York SW, Nunn D, Shanmugam KT, Ingram LO (2009a) Furfural inhibits growth by limiting sulfur assimilation in ethanologenic Escherichia coli strain LY180. Appl Environ Microbiol 75:6132-6141

Miller EN, Jarboe LR, Yomano LP, York SW, Shanmugam KT, Ingram LO (2009b) Silencing of NADPH-dependent oxidoreductase genes ( $y q h D$ and $d k g A)$ in furfural-resistant ethanologenic Escherichia coli. Appl Environ Microbiol 75:4315-4323

Palmqvist E, Hahn-Hagerdal B (2000a) Fermentation of lignocellulosic hydrolysates. I: inhibition and detoxification. Bioresour Technol 74:17-24

Palmqvist E, Hahn-Hagerdal B (2000b) Fermentation of lignocellulosic hydrolysates. II: inhibitors and mechanisms of inhibition. Bioresour Technol 74:25-33

Purvis JE, Yomano LP, Ingram LO (2005) Enhanced trehalose production improves growth of Escherichia coli under osmotic stress. Appl Environ Microbiol 71:3761-3769 
Taherzadeh MJ, Gustafsson L, Niklasson C, Liden G (2000) Physiological effects of 5-hydroxymethylfurfural on Saccharomyces cerevisiae. Appl Microbiol Biotechnol 53:701-708

Um BH, Karim MN, Henk LL (2003) Effect of sulfuric and phosphoric acid pretreatments on enzymatic hydrolysis of corn stover. Appl Biochem Biotechnol 105:115-125
Wyman CE, Dale BE, Elander RT, Holtzapple M, Ladisch MR, Lee YY (2005) Comparative sugar recovery data from laboratory scale application of leading pretreatment technologies to corn stover. Bioresour Technol 96:2026-2032

Zaldivar J, Martinez A, Ingram LO (1999) Effect of selected aldehydes on the growth and fermentation of ethanologenic Escherichia coli. Biotechnol Bioeng 65:24-33 